\title{
Reconocimiento débil: derechos de pueblos indígenas en Chile
}

\author{
Claudio Fuentes*, Maite de Cea**
}

Perfiles Latinoamericanos

Flacso México

\begin{abstract}
Resumen
Después de diecisiete años de discusión, el Congreso en Chile aprobó la suscripción de este país al Convenio 169 de la oit que obliga al Estado a consultar a los pueblos indígenas sobre los temas que los afectan directamente. Como las condiciones políticas e intereses económicos no eran favorables, sorprende este resultado debido a que en la región Chile es uno de los países más retrasados en dicha materia. Con base en un detallado análisis, en este artículo se sostiene que ciertos giros legales y una creciente presión del movimiento indígena impulsaron un cambio en la estrategia de la derecha política. A esto se suma la mayor aceptación de legisladores que representan territorios con alta concentración indígena. Se trata de una adaptación discursiva hacia un reconocimiento débil en un contexto político caracterizado por una fuerte resistencia a la diversidad.
\end{abstract}

\begin{abstract}
After seventeen years of debate, the Chilean Congress approved the ilo 169 Convention on indigenous rights that compels the State to consult indigenous communities on issues that directly affect them. As the political and economic conditions were unfavourable, this political outcome is surprising. Indeed, the legal status of the indigenous people in Chile is weaker than in the rest of Latin America. This article explains this outcome through a detailed description of institutional changes as well as social pressures from the indigenous movement. These factors made right-wing sectors to adapt their discourses in order to accept Chile as a multicultural society. Moreover, a relevant part of the story is related to territorial differences among legislators. Discourse adaptation toward a soft recognition of indigenous rights is a likely outcome in a very conservative environmental setting.
\end{abstract}

Palabras claves: pueblos indígenas, Chile, reconocimiento, Convenio 169 de la oIT, movimiento social, proceso político, nacionalismo, consulta indígena.

Keywords: Indigenous, Chile, recognition, ilo 169 Convention, social movement, political process, nationalism, indigenous consultation.

* Doctor en Ciencia Política, Universidad de Carolina del Norte (Chapel Hill). Profesor, Universidad Diego Portales (Chile), investigador asociado del Centro de Estudios Interculturales e Indígenas CIIR-FONDAP.

** Doctora en Ciencia Política, Institut d'Études Politiques de Grenoble, Francia. Profesora, Universidad Diego Portales (Chile), investigadora asociado del Centro de Estudios Interculturales e Indígenas CIIR-FONDAP. 


\section{Introducción ${ }^{1}$}

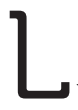

uego de dieciocho años de tramitación en el Congreso, en 2008 se aprobó en Chile la aceptación del Convenio 169 de la Organización Internacional del Trabajo (огт) por el cual se establece la obligación de los Estados de consultar a los pueblos indígenas en temas que los afecten directamente. Esta aprobación resulta inesperada debido a la vigencia de dos condiciones que explicarían la resistencia al cambio: el predominio de grupos políticos conservadores en el Congreso, y fuertes intereses económicos de la industria extractiva que afectan directamente los intereses de las comunidades indígenas.

En efecto, desde el inicio de la transición, las fuerzas políticas reformistas propusieron reiteradamente el reconocimiento constitucional de los pueblos originarios y la mayor explicitación de sus derechos. Sin embargo, esa propuesta encontró el rechazo de los partidos de derecha que hasta 2013 controlaron al menos una de las Cámaras. Pero además el modelo económico chileno depende mucho de los sectores mineros, forestales, pesqueros y energéticos, los cuales han estado interesados en impulsar proyectos extractivos afectando territorios reclamados por comunidades indígenas.

En este artículo explicamos las causas del en apariencia imprevisto resultado que se refiere arriba y que sin duda afecta a los poderosos. Se pretende así enriquecer la literatura sobre el reconocimiento de los pueblos originarios en América Latina. Aceptando la idea de la existencia de coyunturas críticas favorables y de la importancia de alianzas de poder entre el movimiento social y actores políticos, se busca contribuir esclareciendo la dinámica política de aceptación de la diversidad étnica en una sociedad. Para ello, en una primera parte se discuten los determinantes del reconocimiento; luego se analizan los determinantes socioinstitucionales que afectarán al discurso y actitudes de los actores sobre el reconocimiento en Chile, para, finalmente, dar cuenta de la adaptación estratégica de los actores políticos y las diferencias territoriales en los patrones de votación que explican la aprobación del Convenio 169 de la OIT.

1 Este trabajo se realizó en los marcos del Centro de Estudios Interculturales e Indígenas (CIIR), donde los autores son investigadores asociados, del proyecto FONDECYT 1120206, y del Proyecto Núcleo Milenio NS 130008. Los autores agradecen los comentarios de los revisores anónimos y de los editores de Perfiles Latinoamericanos 


\section{Los determinantes del reconocimiento}

Una de las mayores transformaciones en América Latina es el reconocimiento formal de los pueblos originarios en las Constituciones nacionales. En poco más de veinte años, prácticamente todos los países de América Latina adaptaron sus cartas magnas de diferentes modos a la existencia de diversidad cultural y/o a sus pueblos originarios (Burguete, 2008; Yrigoyen, 2009). Aunque se trata de un hecho más bien formal y no social ni cultural, se ha sostenido que estos cambios han dinamizado otros posteriores. Por lo mismo, el reconocimiento legal/formal es solo un paso básico en el avance de los derechos de los pueblos originarios. Estudiando los casos de Colombia y Bolivia, Van Cott (2000) seńala que aunque el contexto social de ambos países es muy distinto (Colombia con un $2 \%$ de población indígena y Bolivia con 60\%), lo que es relevante es la coyuntura crítica de cada uno. En el caso de Colombia se produjo una crisis política que abrió el camino para que desde los movimientos sociales y políticos se demandara una asamblea constituyente que se materializó en la nueva Constitución de 1991. En Bolivia, aunque también se enfrentó una crisis de legitimidad constitucional, tal cambio político se dio desde "arriba", impulsado por la Presidencia, la cual incorporó una reforma constitucional en 1994 que incluía el reconocimiento indígena. Crisis políticas significativas, actores sociales movilizados y agentes en posiciones de poder relevantes parecerían cristalizar diferentes trayectorias de reconocimiento.

Otros estudios muestran que las crisis de gobernabilidad o la estructura de oportunidades políticas han sido fundamentales para explicar políticas de reconocimiento (Anaya, 2005; Villalba, s/f). Aquí la explicación principal es la forma en que los actores sociales y políticos responden en contextos de crisis de gobernabilidad. Luego de analizar cinco casos (Argentina, Brasil, Colombia, Paraguay y Venezuela), Villalba concluye que la combinación más destacada para apreciar un amplio nivel de reconocimiento se considera cuando ocurre una revisión total de la Constitución, cuando dicho proceso se realiza en un contexto de crisis de legitimidad, y cuando se produce una participación efectiva de indígenas en asambleas constituyentes.

A ello se suma el establecimiento de alianzas en el proceso político de reconocimiento. Anaya (2005), por ejemplo, estudia los casos de Oaxaca y Chiapas en México argumentando que es vital comprender cómo se incide en la toma de decisiones. Para este autor, el establecimiento de alianzas entre grupos indígenas y actores claves del sistema político es parte esencial de la explicación de este reconocimiento legal.

Un tercer elemento es el relativo a la presión y características del movimiento indígena, ya sea por su tipo de demanda (de "autodefensa" o "indígenas cam- 
pesinos") o por el tipo de agenda que hayan desarrollado (demandas acotadas, reconocimiento multicultural, o autonomía) (Yashar, 2005; Marti, 2010). La literatura ha puesto de relieve la importancia de la presión social como condición para el avance en derechos (Bengoa, 2000; Yashar, 2005), aunque también se han identificado resultados mixtos (Bengoa \& Caniguan, 2012).

Un tema adicional que varios autores han discutido es la no neutralidad del "reconocimiento". En diversos casos se le ha concebido como una estrategia de los actores que detentan el poder para frenar avances posteriores en materia de autonomía. Esto es, se acepta el reconocimiento formal-legal de la multiculturalidad para impedir demandas de mayor envergadura como "autonomía" y "autogobierno". Pero además, muchas políticas asociadas al reconocimiento esconden mecanismos de implementación que lo entorpecen o lo hacen inoperable (Van Cott, 2000; Hale, 2002; Bello, 2004; Burguete, 2008).

El reconocimiento constitucional es un primer paso simbólico que eventualmente generaría mayores niveles de concreción de derechos indígenas. En América Latina se han experimentado tres oleadas distintivas: una primera de aceptación de la "diversidad cultural", una segunda de "multiculturalidad" y una tercera de "plurinacionalidad" (Yrigoyen, 2009). Costa Rica, Uruguay, Chile, Honduras y El Salvador son las excepciones que no han incorporado el reconocimiento de pueblos originarios constitucionalmente, aunque algunos de ellos sí lo hacen en normativas de menor rango.

Tal como Van Cott lo anticipaba, un elemento esencial que explica el reconocimiento legal es la aparición de una crisis política mayor, a lo cual se deberían agregar las coyunturas transicionales. De hecho, en diez de los doce casos de reconocimiento constitucional se observa un vínculo con la promulgación de nuevas Constituciones luego de una transición o como producto de una crisis política relevante. Siguiendo el argumento de Van Cott, los procesos de redefinición constitucional produjeron coyunturas críticas que posibilitaron que representantes de pueblos originarios o sus aliados políticos no indígenas incidieran en el proceso político.

A este ciclo político de reconocimiento constitucional se debe añadir la suscripción a tratados internacionales para establecer una protección especial de los pueblos originarios, de estos, el Convenio 169 de la ort de 1989 es el más significativo. $^{2}$ Este Convenio marcó un nuevo derrotero internacional al reconocer la identidad de tales pueblos, aspecto que ningún Estado o grupo social

2 Los tratados internacionales más relevantes para América Latina son la Convención sobre el Instituto Indigenista Interamericano (1940), el Convenio 107 de la orT sobre Poblaciones Indígenas y Tribales en países independientes (1957), el Convenio 169 de la oIT (1989), y la más reciente Declaración de las Naciones Unidas sobre los Derechos de los Pueblos Indígenas (2007). 
puede ya desconocer. Lo anterior implica tanto la responsabilidad de desarrollar acciones para proteger sus derechos por parte de los Estados, como el deber de estos de consultar a los pueblos cada vez que se tomen medidas legislativas o programas que los afecten. Una vez suscrito el Convenio 169, los Estados deben comprometerse a establecer procedimientos de buena fe y a través de sus instituciones representativas, lo que implica que los pueblos originarios participen efectivamente en la formulación, ejecución y evaluación de los planes y programas de desarrollo nacional y regional. Asimismo, al reconocer la existencia del derecho consuetudinario y de las costumbres indígenas, se establece la necesidad de incorporar medidas para asegurar el pluralismo legal. Y también se insta a los gobiernos a adoptar medidas especiales para salvaguardar las personas, instituciones, bienes, trabajo, culturas y el medioambiente de estos pueblos.

En América Latina, catorce países han ratificado el Convenio 169 y cuatro no lo han hecho (Cuba, El Salvador, Panamá y Uruguay). Como podría esperarse, hay un vínculo entre el reconocimiento constitucional y tal ratificación (Van Cott 2000). En ocho de los catorce países el Convenio 169 fue ratificado dentro de los dos años que siguieron a la aprobación de una nueva Constitución.

Como anticipábamos, el caso de Chile se distingue por su lento avance. Observamos la ausencia de una cláusula constitucional que reconozca a los pueblos originarios, pese a que se ha discutido en el Congreso por 24 años y la aprobación del Convenio 169 demoró diecisiete años. Desde el punto de vista de la teoría de recursos de poder (Korpi, 1998), intuitivamente se explica esta circunstancia. Como el balance de poder ha favorecido a las fuerzas conservadoras de derecha desde el retorno de la democracia, y como aquellas han sido las más renuentes a tal reconocimiento, es plausible esperar que este cambio se haya concretado. ${ }^{3}$ Aunque tanto la población indígena (10\%) como el movimiento indígena que la sustenta son significativos, los avances institucionales han sido lentos producto de este bloqueo.

Pese a que la coalición de centro-izquierda (Concertación) que gobernó Chile entre 1990 y 2010 presentó varios proyectos de ley para materializar tal reconocimiento, ${ }^{4}$ siempre se encontró con la oposición de la derecha que, o

3 Chile es un sistema presidencial con un Congreso bicameral. Entre 1990 y 2005, la coalición de derecha siempre mantuvo la mayoría en el Senado. En 2006 se produjo una situación especial que permitió que el gobierno de centro-izquierda obtuviera la mayoría de ambas Cámaras, pero divisiones internas hicieron que la perdiera en 2007. En todo caso, la reforma constitucional de reconocimiento de pueblos originarios requiere de dos tercios de ambas Cámaras para su aprobación con lo que esto resultaba imposible sin el apoyo de la Alianza.

4 Entre 1990 y 2011 el Congreso nacional discutió nueve proyectos que directa o indirectamente abordaban el tema del reconocimiento. Salvo la ratificación del Convenio 169, los otros ocho proyectos o fueron archivados (5) o se mantienen en trámite (3). 
tenía la mayoría de una de las Cámaras o mantenía un importante poder de veto (el quórum para la aprobación de una reforma de esta naturaleza era muy alto: dos tercios de ambas Cámaras). La resistencia es coherente con una postura ideológica conservadora y nacionalista que valora la "unidad de la nación" y con fuertes intereses económicos, dadas las iniciativas productivas que afectan territorios indígenas. ${ }^{5}$ El debate adquiría así tanto una dimensión ideológica como otra económica, y de ahí su importancia.

\section{Determinantes macroestructurales: cambio socioinstitucional}

El proyecto de ratificación del Convenio 169 se presentó en el Congreso en 1991. Pero recién en el año 2000 se votó y aprobó en la Cámara de Diputados. Por tratarse de una ley simple, requería del 50\% más uno de los votos para su aprobación, pero obtuvo finalmente el apoyo del $60 \%$. Ocho años más tarde el Senado votó el proyecto, el que se aprobó con el 94.7\% de los votos. La tramitación completa demoró diecisiete años, pero en ambas Cámaras algunos parlamentarios de la derecha concurrieron a aprobar la iniciativa.

Para entender el proceso de aprobación debemos atender dos factores socioinstitucionales: el gradual proceso de reconocimiento a partir de la institucionalización de legislación que requiere de mayoría simple o de "bajo nivel", y la creciente presión social del movimiento indígena que ha estimulado una adaptación discursiva de los actores políticos —en particular de los actores de veto de derecha-, los que han aceptado progresivamente la idea del reconocimiento, aunque bajo condiciones restrictivas que especificaremos más adelante.

\section{Institucionalización progresiva de la diferencia}

Un primer aspecto relevante es la institucionalización progresiva de derechos indígenas. Desde 1990, han habido avances legales en torno al reconocimiento de minorías étnicas, protección social, patrimonio y desarrollo. Pese a que en el periodo no se evidenciaron avances en normas de "alto nivel" (esto es, constitucionales), sí se ven progresos en legislaciones de menor rango. De hecho, de los 78 proyectos presentados al Congreso entre 1990 y 2011, trece fueron aprobados, treinta rechazados, y treinta y cinco se encuentran en trámite. El mayor número de iniciativas corresponde a propuestas referidas al reconoci-

5 De acuerdo al Consejo Minero, desde 2010 y hasta 2013 se habían retrasado proyectos de inversión minera y eléctrica por $33000 \mathrm{mdd}$. Los proyectos paralizados por presión de comunidades sumaban nueve mil mdd, que según el Consejo era lo más alto de América del Sur. 
miento a estos pueblos, a las que siguen aspectos vinculados a desarrollo y beneficio social. De las trece aprobadas, la mayor parte corresponde a iniciativas vinculadas a reconocimiento en sus diferentes graduaciones.

Entre los hitos legales más significativos destacan la aprobación de la Ley Indígena (1993) que establece una institucionalidad para la protección, fomento y desarrollo de los pueblos; la creación del Fondo de Desarrollo Indígena (1996), y la materialización de un espacio marítimo costero para los pueblos originarios en zonas utilizadas ancestralmente (2008), entre otros. Pero el hito legislativo más relevante ha sido la aprobación del Convenio 169 de la oit (2008), que establece el mandato de consulta a los pueblos originarios.

Lo importante de destacar es que primero se aprecia una dinámica de aprobación legislativa que aborda temáticas productivas o de desarrollo, institucionales, restitución, interculturalidad y propiamente de reconocimiento. Lo segundo es que tales avances han contado con el apoyo político de algunos sectores de derecha. Aunque el balance de poder en el Congreso no se ha alterado significativamente en el periodo bajo análisis, se produjo una gradual institucionalización y reconocimiento de los pueblos originarios. Mientras proyectos "productivistas" concitaban un rápido consenso político, los concernientes a "reconocimiento" provocaban mayor resistencia. ${ }^{6}$

La existencia de un veto político al reconocimiento incentivó a las autoridades a la estrategia de impulsarlo gradualmente desde normas de menor rango constitucional. Aunque el avance legal ha sido lento y deficitario (Mariman \& Aylwin, 2008), sin duda ha establecido un proceso de reconocimiento que ha dinamizado el debate público, las estrategias y demandas del propio movimiento social indígena y las exigencias por reconocimiento.

\section{Presión social indígena}

Junto a la gradual implementación de normas atingentes a derechos de pueblos originarios, se ha intensificado la protesta social indígena — sobre todo la mapuche en el sur de Chile- . Toledo (2007) explicita de forma convincente los dos ciclos de protesta indígena de posdictadura: el 1990-1994 y el 19972004. Cabe añadir un tercer ciclo del que marcamos su inicio en 2007 y que con altos y bajos ha perdurado hasta la actualidad. El primer ciclo se asocia tanto al retorno a la democracia como a la conmemoración de los quinientos

6 Los proyectos asociados a reconocimiento, restitución de territorios e interculturalidad tardan en promedio cinco ańos para aprobarse, mientras la legislación nacional promedia dos ańos. Por su parte, los proyectos de ley orientados a la protección social y el desarrollo de los pueblos originarios, demoran 1.85 años en promedio para aprobarse. 
años de la llegada de Colón a América (Toledo, 2007). En esta etapa se aprobó la ley indígena y se implementó a partir de dicha norma la Corporación Nacional de Desarrollo Indígena (CONADI).

El segundo ciclo inicia en 1997 cuando se implementan proyectos forestales y energéticos que afectaron los derechos del pueblo mapuche sobre sus territorios. En este periodo se cuenta la construcción de una megacentral hidroléctrica en la cuenca del alto Bío Bío y la ocupación de tierras ancestrales en Lumaco. La respuesta del Estado se relaciona principalmente con políticas de subsidios y entrega de tierras. Ante esta presión social la Cámara de Diputados aprueba el Convenio 169 (2000) y se crea la Comisión de Verdad Histórica y Nuevo Trato (2002) que tendría muy poco impacto posterior.

Un tercer ciclo de activismo tuvo un clímax en 2008. Entonces se radicalizó la protesta social y se produjo una importante reelaboración de contenidos culturales por parte de los nuevos dirigentes mapuche (Bengoa \& Caniguan, 2012). Dos momentos culminantes fueron el asesinato por la espalda del joven Matías Catrileo por parte de un carabinero (enero de 2008), lo que desencadenó una serie de protestas de grupos indígenas y de la comunidad internacional, y la huelga de hambre de 82 días que protagonizaron indígenas detenidos en prisión preventiva (julio-octubre de 2010). Este tercer ciclo coincide con la aprobación del Convenio 169 en el Senado. De hecho, su aprobación final en el Congreso aconteció dos meses después de la protesta que involucró el asesinato de Catrileo.

Pero la intensificación de la protesta se asocia también a las mayores demandas de la industria extractiva por acceso a recursos naturales, y a crecientes necesidades energéticas que han presionado áreas territoriales con presencia indígena. Para ilustrarlo, cabe indicar que de los 97 conflictos medioambientales en Chile a junio de 2012, 33 (34\%) afectaban territorios indígenas; los principales eran quince proyectos de explotación minera y nueve que involucraban proyectos energéticos (INDH, 2012). El presidente del Consejo Minero, Joaquín Villarino, defendiendo la postura del gran empresariado sostenía que: "la aplicación del Convenio ha sido un desastre. En el Congreso no se dieron cuenta de lo que están aprobando dado que la forma en que se ha aplicado el Convenio ha sido un obstáculo para el desarrollo de la industria minera. Ningún país minero ha aprobado este Convenio"?

Villarino, J. (2013, 16 de octubre). Presidente Ejecutivo del Consejo Minero le pasa la factura a sus colegas de la industria energética y a los empresarios agrícolas. El Mostrador. Recuperado el 28 de noviembre de 2013, de http://www.elmostradormercados.cl/sin-editar/presidente-ejecutivo-del-consejominero-le-pasa-factura-a-sus-colegas-de-la-industria-energetica-y-a-empresarios-agricultores/ 


\section{Reconocimiento débil: el discurso conservador}

En un contexto de lenta institucionalización de políticas pro reconocimiento e intensificación de protesta indígena, la respuesta esperada de las fuerzas conservadoras era su rechazo basado en intereses económicos (en defensa del modelo extractivista) y argumentos ideológicos (la protección de la identidad nacional y el prejuicio y discriminación hacia los pueblos indígenas) (De Cea, 2012). En esta sección explicamos que parte de la derecha optó por una adaptación estratégica aprobando el Convenio 169. Pero al mismo tiempo vemos que se producen diferencias dentro de los actores de derecha: los que representan a territorios con alta presencia indígena se muestran más receptivos al reconocimiento de derechos ya sea por la vía constitucional o por vía de la aprobación de un tratado internacional.

\section{Unidad nacional, racismo y pueblos originarios}

La construcción de lo "nacional" nos remonta a las luchas por la independencia, cuando se forjó una identidad común en las primeras dos décadas del siglo XIx. El triunfo del modelo conservador y su materialización en la Constitución de 1833 resignificó el sentido de lo "nacional". En efecto, las élites conservadoras (hombres, criollos, no indígenas) que se impusieron a otros grupos de la sociedad que aspiraban a un modelo político federalista, se alinearon en torno "a una visión territorial y geopolítica de la nación, donde la estabilidad político-social y el progreso material pasaron a reemplazar a la ciudadanía o a la democracia como marcadores esenciales del republicanismo" (Pinto \& Valdivia, 2009: p. 335). A ello se agregaría el fenómeno de la guerra como factor de unidad que daría todavía mayor sustento al discurso nacionalista, enfrentados a amenazas tanto internas (la Araucanía) como externas (Bolivia y Perú) (Figueroa, 2013).

Esta noción se proyectaría en el siglo xx. A diferencia de otras realidades en América Latina, la élite política chilena de derecha no enfrentó amenazas de élites regionales y se separaba entre una más conservadora y una más liberal. En ambas vertientes predominó una visión discriminadora y racista respecto de los indígenas, particularmente en relación al pueblo mapuche que mantuvo una tenaz resistencia a su incorporación al territorio chileno (Foerster \& Montecino, 1988; Antileo, 2012). Predominaba en la élite una noción de proyecto nacional y "civilizatorio" en la que solo la asimilación de los indígenas permitiría su desarrollo (Boccara, 1999; Bello, 2011). El escenario de fines del siglo xx estuvo marcado por la dictadura militar de Pinochet. La derecha 
— expresada a comienzos de los setenta en el Partido Nacional y el gremialismo- apoyó activamente el establecimiento, consolidación y proyección del régimen (Huneeus, 2000). A fines de los ochenta surgieron el partido Renovación Nacional (RN) y la Unión Demócrata Independiente (UDI), que organizó a las fuerzas del gremialismo. A ambos partidos los unía su férrea defensa del modelo económico neoliberal y esta noción que venimos destacando respecto de la identidad indivisible de la nación chilena.

Muñoz-Navarro (2008) concluye que existen dos fuentes para la consolidación del sentido de nación entre la derecha chilena. Las guerras de la independencia que permitieron a la élite establecer una "comunidad imaginada" integrando al bajo pueblo y a los indígenas en este ideario común en contra de la amenaza externa; y la glorificación simbólica del indígena por su amor a la libertad. Según Gallardo, "los indios fueron incorporados a la nación e invitados a la participación en igualdad; para el cumplimiento de esa utopía igualitaria fue preciso desarrollar un discurso que negara al indio en tanto otro, alterno y distinto" (Gallardo, 2001: p. 1). Estudios posteriores sobre la élite política y económica confirman la preponderancia de nociones racistas y discriminadoras, en particular respecto del pueblo mapuche (De Cea, 2012). Como varios autores han enfatizado, desde la invasión del territorio mapuche se reforzó constantemente la construcción del sujeto mapuche como "violento" (y recientemente "terrorista") predominando una actitud centrada en el paternalismo colonial y el racismo (Correa \& Mella, 2010; Richards, 2013).

Cuando la Concertación asumió el poder en 1990 una de sus primeras propuestas fue que "el Estado velará por la adecuada protección jurídica y el desarrollo de los pueblos que integran la nación chilena”. ${ }^{8}$ Esta iniciativa reafirmaba la existencia de una sola nación, pero que dentro de ella existían varios "pueblos". La idea fue rechazada por la derecha. En el año 2000, un grupo transversal de congresistas que incluía a representantes de la derecha, formuló una nueva propuesta que establecía que "El Estado reconoce a los pueblos indígenas, los cuales integran la nación chilena. La ley promoverá el respeto y desarrollo de sus culturas, lenguas, organización social y costumbres, y garantizará a sus integrantes la participación que les corresponde en iguales términos que a todos los demás chilenos" (Boletín 513-07: pp. 29-30). Nuevamente se buscaba reconocer a los pueblos y al mismo tiempo asociarlos como integrantes de la nación chilena, garantizán-

8 Proyecto de ley relativo a la protección, fomento y desarrollo de los pueblos indígenas, Boletín No. 514, 15 de octubre, 1991. Cámara de Diputados. 
doles, como al resto, una participación en igualdad de condiciones. Tampoco se aceptó esta idea. ${ }^{9}$

Para los sectores conservadores la unidad de la nación no podía ponerse en cuestión, dado que la sociedad chilena en la práctica había incorporado a los indígenas sin hacer diferencias: "la historia de Chile muestra diversos casos de chilenos de origen mapuche que han ocupado puestos de conducción y se han integrado plenamente a la sociedad" (exalmirante Martínez, HL No. 20.050: p. 91). En la misma línea, el senador Diez (RN) planteaba que "lo verdaderamente importante era determinar si la sociedad en la práctica ha incorporado a su seno dichos pueblos sin hacer diferencias. Esto ha sido posible no obstante que ninguna Constitución nuestra ha estimado necesario dividir a los chilenos según su origen" (HL N. 20.050: p. 91).

En esta mirada, Estado y nación se identificaban como una sola entidad. Sostenía el abogado Ribera (RN) que "en nuestro país la concepción de Estado se ha basado desde la independencia, en la identidad entre el estado y la nación y en la circunstancia de que el hombre es la base de toda estructura estatal y sujeto por esencia de los derechos y libertades" (HL N 20.050: p. 1005). Desde esta perspectiva, se integra la identidad indígena propiamente como tal a la concepción de la nación. Según Ribera, y aludiendo al pueblo mapuche, "su presencia es relevante en nuestra identidad nacional pues son una base de la nacionalidad. Sin mapuches no existirían los chilenos. Si el 80\% de los chilenos somos mestizos, ¿Qué son, entonces, los mapuches?” (HL Nº. 20.050: p. 1012).

A esta postura se suma el argumento referido de que no sería recomendable establecer distinciones entre las personas. El senador Larraín (UDI) destacaba que Chile es un país unitario y que desde el siglo "antepasado hay igualdad entre todos sus integrantes, la que se acogió en el Código Civil en forma bastante clara cuando éste dispuso que no existen diferencias entre chilenos y extranjeros" (HL No. 20.2050: p. 96).

Pero esta noción nacionalista-liberal comenzó a tensionarse cuando algunos actores políticos de la propia derecha constataban las brechas de pobreza y discriminación en que se encontraban los indígenas. El mismo senador Larraín planteaba que tales problemas deberían resolverse mediante políticas públicas para garantizar "un desarrollo socioeconómico acorde con la realidad del país, con igualdad y armonía, con un mayor reconocimiento y mejores canales de participación y, en especial, con un fomento de las culturas indígenas que están perdiendo su identidad" (Boletín 5324-07, diario 2).

9 Esta propuesta fue aprobada por cinco votos contra tres en la Comisión de Derechos Humanos, aunque no logró su aprobación en la Cámara de Diputados y se archivó en octubre de 2000. 
Un reconocimiento débil, entonces, permitiría disminuir conflictos latentes. Sostenía el senador Chadwick (UDI) que "la carta fundamental dignifica a las personas, cualquiera sea su origen, no obstante lo cual es conveniente introducir en ella un reconocimiento a las comunidades indígenas que conforman la identidad para atenuar, en alguna forma, los conflictos latentes" (HL $\mathrm{N}^{\circ} 20.2050$ : p. 1042). Así, el otorgamiento de derechos especiales se convirtió en una estrategia instrumental para evitar la exacerbación de demandas de autonomía, más que la aceptación sustantiva de determinados derechos —véase el debate en Aylwin (2013).

En 2007 se intensificaron las protestas del pueblo mapuche. Y el Estado respondió aplicando políticas represivas contra la protesta social, tal cual había sucedido desde el inicio de la transición (Toledo, 2007). Desde el punto de vista legislativo, en septiembre de 2007, un grupo de senadores de RN propuso una moción que estipulaba que "la nación chilena es una e indivisible, reconoce y valora la contribución de los pueblos indígenas originarios, definidos como grupos de culturas anteriores a la organización del Estado y a la conformación del pueblo chileno. Es deber del Estado respetar la identidad, cultura y tradiciones de sus raíces ancestrales" (Boletín 5324-07). ${ }^{10}$ Con este fraseo, un sector de la derecha comenzó por primera vez a aceptar el vocablo "pueblo", aunque siempre destacando la indivisibilidad de la nación. En el debate legislativo, el senador Espina (RN), planteaba que se proponía reconocer derechos de las comunidades indígenas "otorgando el derecho a los pueblos indígenas para organizar su vida de acuerdo a sus costumbres siempre que ello no contravenga la Constitución y las leyes" (Boletín 5324-07).

Esto constituye un cambio relevante respecto de las visiones predominantes hasta esa fecha. Un reconocimiento tenue dentro de la nación era la respuesta de la derecha. Así lo reafirmaba el senador Larraín: "la nación es una e indivisible, pero multicultural, lo que refleja en armonía y en complementación, las realidades nacionales. Una sola nación pero muchas culturas que la integran, sin superioridad de ninguna de ellas, configura el Chile de todos" (Boletín 5324, diario 2).

En 2008 el Senado discutía la ratificación del Convenio 169. Los parlamentarios de derecha habían solicitado el pronunciamiento del Tribunal Constitucional sobre la inconstitucionalidad del tratado. Pero el Tribunal, al revisar este requerimiento, rechazó la solicitud (Donoso, 2008), aludiendo que no había un quiebre entre las normas del Convenio y las de la Constitución. ${ }^{11}$

Originalmente, la justificación de los legisladores de derecha para no aprobar este Convenio era que esta norma establecía dos ciudadanías, la indígena

10 Moción presentada por los senadores Allamand, Cantero, Espina, Romero y García.

11 El requerimiento fue enviado por 31 diputados, catorce de RN y diecisiete de la UDI. 
y la chilena, lo que contradecía lo postulado por la Constitución chilena: "Todos somos chilenos, aunque tengamos orígenes distintos (mapuches, aimaras, alemanes, españoles) y la igualdad ante la ley, porque no se pueden establecer discriminaciones arbitrarias, al tenor del artículo 19, No $3^{\circ}$ " (Senador Larraín, HL Decreto No 236: p. 307). ${ }^{12}$

Pero luego del asesinato de Matías Catrileo en 2008 por carabineros, aumentaron las protestas indígenas. A esto se sumaban más quemas de predios forestales por grupos que la justicia no lograba identificar. En febrero de ese año, la Gendarmería concedió beneficios carcelarios a una activista mapuche que cumplía más de cien días en huelga de hambre, lo que ocasionó críticas desde la derecha. De igual modo, los sectores más conservadores demandaron del gobierno medidas más drásticas para reducir los hechos de violencia y castigar a sus responsables. ${ }^{13}$ Mientras que sectores más moderados pidieron una revisión de los programas de pobreza y una evaluación de las políticas públicas por considerar que no estaban cumpliendo su labor de atender las demandas indígenas. ${ }^{14}$ En un contexto de alta tensión social, los senadores de derecha aceptaron la idea de aprobar el Convenio bajo dos condiciones. Primero, que el concepto "pueblo" se entendería en su sentido sociológico y no jurídico, ratificando la indivisibilidad de la nación chilena (Boletín 5324-07). En segundo lugar, todas las fuerzas políticas en el Congreso aceptaron la propuesta de los senadores Coloma (UDI) y Romero (RN) agregando a dicha aprobación una "declaración interpretativa" del artículo 35 del referido Convenio. En este artículo quedaba establecido que "la aplicación de las disposiciones del presente Convenio no deberá menoscabar los derechos y las ventajas garantizados a los pueblos interesados en virtud de otros convenios y recomendaciones, instrumentos internacionales, tratados, o leyes, laudos, costumbres o acuerdos nacionales". La declaración señalaba que "el Gobierno de la República de Chile, al ratificar el Convenio 169 de Pueblos Indígenas y Tribales en Paises Independientes, formula una declaración interpretativa al artículo 35, del referido instrumento internacional, en el sentido que este sólo es aplicable en relación a los tratados internacionales ratificados por Chile, y que se encuentren vigentes". De acuerdo a los legisladores que patrocinaron esta

12 El artículo 19, núm. 3, establece la igual protección de la ley en el ejercicio de los derechos de las personas.

13 Sostenía el senador Novoa que: "(Primero) hay que dar una señal clara de que no se toleran atentados y que van a ser perseguidos con todo el rigor de la ley, y segundo, tener una política indígena absolutamente distinta a la actual, que es ceder a las presiones para adquirir tierras". En El Mercurio. (2008, 30 de enero). Parlamentarios aliancistas acusan fracaso de La Moneda tras ceder ante huelguista. Recuperado el 3 de diciembre de 2013, de http://diario.elmercurio.com/detalle/index. asp?id= $\{\mathrm{c} 9 \mathrm{f} 43 \mathrm{~d} 8 \mathrm{c}-\mathrm{d} 1 \mathrm{ac}-4 \mathrm{c} 5 \mathrm{f}-\mathrm{a} 5 \mathrm{ad}-3 \mathrm{a} 45 \mathrm{cb} 5 \mathrm{~d} 9 \mathrm{bd} 0\}$

14 Radio Cooperativa (2008, 13 de enero). "Senador Allamand pidió que se realice una auditoría en la Conadi”. Recuperado el 3 de diciembre de 2013, http://www.cooperativa.cl/noticias/pais/senadorallamand-pidio-que-se-realice-una-auditoria-en-la-conadi/2008-01-12/122343.html 
declaración, lo que se pretendía era limitar su aplicabilidad a los instrumentos en los que hubiera un claro e inequívoco consentimiento del Estado, como en el caso de los tratados ratificados por Chile que se encuentran vigentes. Posteriormente, el Tribunal Constitucional y la OIT no aceptaron aquella declaración interpretativa, por lo que el Convenio entró en vigor sin aceptarse aquel condicionamiento del Estado chileno.

A ello debemos sumar el posterior y accidentado proceso de aprobación del reglamento específico para realizar las consultas a los pueblos indígenas, el que ha encontrado gran resistencia entre el sector empresarial. Los gobiernos de Bachelet, primero, (2009) y el de Piñera, después (2013), establecieron procedimientos administrativos para operar la consulta fuertemente cuestionados por las comunidades indígenas (Sanhueza, 2013) en ambos casos.

En definitiva, es clara una adaptación discursiva de los actores de derecha. Enfrentados a un contexto de mayor presión social, estos actores que históricamente han rechazado el reconocimiento de derechos (en especial, los colectivos), estratégicamente se abrieron a adaptar su discurso para evitar que nuevas demandas florecieran.

\section{La representación territorial y el reconocimiento}

Al cambio estratégico del discurso de la derecha se suma un comportamiento territorial diferenciado. Es manifiesto que los legisladores que representan a territorios de alta presencia indígena presentan una actitud y un comportamiento legislativo más receptivo al reconocimiento, sin ser ellos de origen indígena.

En relación a las actitudes, durante 2011 aplicamos un censo a los congresistas chilenos, abordando en concreto la temática del reconocimiento. Al realizar la distinción entre congresistas que representan la zona de la Araucanía (catorce, en total), la región que concentra la atención de las demandas del pueblo mapuche, y el resto del país (144, en total), advertimos que prácticamente todos apoyaban el reconocimiento constitucional a pueblos originarios (trece de los catorce lo apoyan), cuestión que no ocurría cuando considerábamos el total. Asimismo, esos congresistas mostraban una mayor predisposición a permitir una ley de cuotas con asientos especiales para indígenas en el Congreso $\mathrm{Na}$ cional, y mayor predisposición a que el Estado entregara beneficios especiales a personas por el hecho de ser indígenas. Pero además mientras el resto de los congresistas mayoritariamente percibía la demanda del pueblo mapuche como de recuperación de tierras ancestrales (56.3\%), los congresistas de la zona no eran de esa opinión, lo que incorporaba mayor complejidad a su percepción de la situación regional (tabla 1). 
Tabla 1. Percepciones de congresistas sobre discriminación y reconocimiento

\begin{tabular}{|c|c|c|}
\hline Tema & $\begin{array}{c}\text { Congresistas de la } \\
\text { región Araucanía } \\
\text { (total: 14) }\end{array}$ & $\begin{array}{l}\text { Congresistas del } \\
\text { resto del país } \\
\text { (total: 144) }\end{array}$ \\
\hline Reconocimiento constitucional de pueblos originarios (\% de acuerdo) & $92.9 \%$ & $73.6 \%$ \\
\hline $\begin{array}{l}\text { Ley que garantice algunos parlamentarios mapuches en el Congreso } \\
\text { (\% acuerdo) }\end{array}$ & $71.4 \%$ & $43.1 \%$ \\
\hline $\begin{array}{l}\text { Grupo social al que el Estado de Chile debiese entregar más benefi- } \\
\text { cios (\% menciones mapuche) }\end{array}$ & $21.4 \%$ & $2.1 \%$ \\
\hline $\begin{array}{l}\text { "Demandas del pueblo mapuche consisten básicamente en recupe- } \\
\text { ración de tierras" (\% de acuerdo) }\end{array}$ & $35.7 \%$ & $56.3 \%$ \\
\hline
\end{tabular}

La segunda dimensión se refiere a la conducta específica al momento de votar un proyecto de ley, y aquí nuevamente observamos que la variable de representación territorial juega un papel relevante. Para ilustrarlo consideramos tres leyes en las que se tuvo acceso completo al total individual de votaciones. La Ley 20.117 buscaba reconocer la etnia diaguita dentro de la Ley Indígena. La Ley 20.249 establecía un espacio marítimo costero de pueblos originarios respetando el uso consuetudinario por parte de comunidades que comprende una porción de agua y fondo, playa y terrenos de playa fiscales que han utilizado las comunidades indígenas ancestralmente. Se entregaría a una asociación de comunidades indígenas que invocan su uso consuetudinario, estableciéndose planes de manejo, en caso de invocarse la necesidad de extracción de recursos del mar. Finalmente, la discusión de la aprobación del Convenio 169 sobre consulta a pueblos originarios.

Tabla 2. Patrones de votación de la derecha chilena en proyectos sobre pueblos originarios de alta significación

\begin{tabular}{|c|c|c|c|c|}
\hline $\begin{array}{l}\text { Tema y votos necesarios } \\
\text { para aprobación }\end{array}$ & & $\begin{array}{c}\text { Primer trámite } \\
\text { en Cámara de } \\
\text { Diputados }\end{array}$ & $\begin{array}{l}\text { Segundo trámite } \\
\text { en Senado }\end{array}$ & $\begin{array}{c}\text { Tercer trámite } \\
\text { en Cámara de } \\
\text { Diputados }\end{array}$ \\
\hline \multirow{4}{*}{$\begin{array}{l}\text { Etnia diaguita } \\
50 \%+1\end{array}$} & A favor & 47 & 38 & $\mathrm{n} / \mathrm{a}$ \\
\hline & En contra & 1 & - & $\mathrm{n} / \mathrm{a}$ \\
\hline & Abstiene & 12 & - & $\mathrm{n} / \mathrm{a}$ \\
\hline & Ausentes & 60 & 0 & $\mathrm{n} / \mathrm{a}$ \\
\hline \multirow{4}{*}{$\begin{array}{l}\text { Espacio marítimo } \\
4 / 7 \text { del Congreso } \\
68 \text { diputados } \\
22 \text { senadores }\end{array}$} & A favor & 80 & 26 & 99 \\
\hline & En contra & - & - & - \\
\hline & Abstiene & 1 & 2 & - \\
\hline & Ausentes & 39 & 10 & 21 \\
\hline \multirow{4}{*}{$\begin{array}{l}\text { Convenio } 169 \\
50 \%+1\end{array}$} & A favor & 72 & 36 & $n / i$ \\
\hline & En contra & 3 & 1 & $\mathrm{n} / \mathrm{i}$ \\
\hline & Abstiene & 11 & - & $\mathrm{n} / \mathrm{i}$ \\
\hline & Ausentes & 34 & 1 & $\mathrm{n} / \mathrm{i}$ \\
\hline
\end{tabular}

Nota: $\mathrm{n} / \mathrm{a}=$ no aplica; $\mathrm{n} / \mathrm{i}=$ no existe información disponible.

Fuente: Elaboración propia. 
En todos los casos se requirió de al menos algunos votos de la derecha para aprobar proyectos incluso con mayoría simple, dado que la derecha controló el Senado durante casi todo el periodo. Lo que se advierte de las votaciones es que el respaldo en la Cámara de origen (la Cámara de Diputados en los tres casos) fue siempre menor que en su paso por el Senado. Se observa así un ciclo de resistencia mayor al inicio de la tramitación, para luego obtener un significativo mayor apoyo - tal vez porque el proyecto es negociado entre el Ejecutivo y Legislativo en la medida que avanza el proceso de tramitación-. Lo que observamos aquí (tabla 3) es el número de votos a favor de estas leyes y el porcentaje de congresistas de derecha que participan de la votación favorablemente, excluyendo a quienes votaron en contra, a los que se abstuvieron y quienes no asistieron a votar.

Tabla 3. Aprobación de proyectos. Votación derecha

\begin{tabular}{|c|c|c|c|}
\hline Tema & Cámara & Votos a favor & Votos de derecha a favor \\
\hline \multirow{2}{*}{ Etnia diaguita } & Diputados & 47 & $15(28.8 \%)$ \\
\hline & Senado & 38 & $17(100 \%)$ \\
\hline \multirow{3}{*}{ Espacio marítimo } & Diputados & 80 & $34(65.4 \%)$ \\
\hline & Senado & 26 & $9(52.9 \%)$ \\
\hline & Diputados & 99 & $44(84.6 \%)$ \\
\hline \multirow{2}{*}{ Convenio 169} & Diputados & 72 & $19(36.5 \%)$ \\
\hline & Senado & 36 & $15(88.2 \%)$ \\
\hline
\end{tabular}

Fuente: Elaboración propia. Durante 2006-2010, el total de diputados de derecha es de 52 y 17 los senadores. Los porcentajes se dan en relación al total de congresistas de la Alianza.

Nos interesaron también las diferencias por partido (tabla 4). Y allí observamos una leve mayor inclinación de los parlamentarios de RN que de la UDI a votar a favor de las iniciativas bajo escrutinio (68\% como promedio de asistencia favorable a votar por Cámara de RN vs. $62 \%$ de la UDI). Lo anterior resulta esperable si consideramos que la UDI por tradición se ubica en la derecha más extrema en cuanto a posturas políticas.

Tabla 4. Aprobación de proyectos. Votación por partido

\begin{tabular}{l|lccc}
\hline Tema & Cámara & Votosa favor & UDI & RN \\
\hline \multirow{2}{*}{ Etnia Diaguita } & Diputados & 47 & $6(18,1 \%)$ & $9(47,3 \%)$ \\
& Senado & 38 & $9(100 \%)$ & $8(100 \%)$ \\
\hline \multirow{3}{*}{ Espacio Marítimo } & Diputados & 80 & $26(78,7 \%)$ & $8(42,1 \%)$ \\
& Senado & 26 & $4(44,4 \%)$ & $5(62,5 \%)$ \\
& Diputados & 99 & $26(78,7 \%)$ & $18(94,7 \%)$ \\
\hline \multirow{2}{*}{ Convenio 169} & Diputados & 72 & $13(39,3 \%)$ & $6(31,6 \%)$ \\
& Senado & 36 & $7(77,8 \%)$ & $8(100 \%)$ \\
\hline
\end{tabular}

Fuente: Elaboración propia. Durante 2006-2010, el total de diputados de derecha fue de 52 (33 de la UDI y 19 de RN). El total de senadores fue de 17 (9 de UDI y 8 de RN). Los porcentajes se dan en relación al total de congresistas por partido. 
Cuando agregamos la variable territorial, advertimos un comportamiento muy diferenciado entre los partidos de derecha. En el caso de RN (más liberal), el $56 \%$ de los casos concurrieron a votar congresistas que tenían electorados con altas tasas de población indígena en sus territorios $(+20 \%)$, mientras que en el caso de la UDI solo ocurrió en $21 \%$. De este modo se infiere un comportamiento diferenciado dentro de los partidos de la derecha chilena — que es la que más resistencia al reconocimiento de pueblos originarios ha tenido desde 1990 - Una conclusión más es que los legisladores de derecha que representan territorios con mayor concentración de población indígena son más proclives a manifestarse a favor del reconocimiento, pero también han concurrido a votar legislación más favorable a tal reconocimiento.

\section{Conclusiones}

La literatura que ha examinado el reconocimiento de pueblos indígenas en América Latina ha realizado una importante contribución analítica al advertir los factores desencadenadores de procesos de transformación y cambio, entre estos la capacidad del movimiento social de presionar por cambios, la existencia de aliados en el sistema político y la constatación de coyunturas críticas, que han sido vistas por dichos estudios como condiciones necesarias para el cambio. Menos atención se ha dado a casos donde estos avances han sido lentos o inexistentes. Nuestro trabajo busca precisamente contribuir a la comprensión de la dinámica política que permite el cambio. Confirmando lo que ya varios estudios han señalado, hemos encontrado que mayores niveles de presión social han generado condiciones para realizar cambios legales. En el caso de Chile, en los dos momentos en que el Congreso decidió aprobar el Convenio 169 (Cámara de Diputados y Senado) se evidenciaban coyunturas de alta conflictividad en el sur del país.

Pero también advertimos una adaptación discursiva en los agentes que defienden el statu quo. La progresiva institucionalización de políticas de reconocimiento y las protestas del movimiento social indígena — sobre todo después de 2007- hicieron que la derecha se abriera a la posibilidad de aceptar la idea de la "multiculturalidad" en lo que denominamos reconocimiento débil por su condicionamiento a la defensa de la identidad del Estado-nación y a la protección de la soberanía respecto del derecho internacional. Explícitamente, la derecha política ha señalado que la aceptación legal del "multiculturalismo" es una concesión estratégica para evitar que conceptos como "autonomía” o "autodeterminación" se instalen en la sociedad. Confirmando lo que otros autores han señalado, concluimos que la aprobación se acompaña de trabas 
en su implementación. Se acepta una norma con la esperanza de que en su implementación fracase.

Ahora bien, en este artículo hay una contribución empírica relevante al constatar divisiones dentro de la derecha política respecto de la problemática del reconocimiento. Los legisladores que representan distritos con altas tasas de población indígena tienden a manifestar una actitud mucho más cercana a la idea del reconocimiento y a votar a favor de estos proyectos.

En este trabajo no se profundiza en la relación legislador-representado, lo que sin duda requiere mayor exploración. Por ejemplo, no sabemos si efectivamente los legisladores advierten una presión de sus electores a la hora de legislar en temas indígenas. Se requiere explorar en forma más específica este tipo de relaciones a fin de observar si efectivamente el patrón de votaciones favorables a los derechos indígenas es producto de un vínculo cercano con sus representados o se debe a otra circunstancia.

Finalmente, nuestro estudio solo se enfoca en la aprobación de normas y no profundiza en su impacto posterior. Tal como lo señala Van Cott (2000), la aprobación de normas contribuye a establecer principios o condiciones mínimas para el ejercicio de los derechos. Las dificultades que ha enfrentado el proceso de implementación del Convenio 169 necesitan un mayor análisis que rebasa con creces el objetivo de este artículo.

No obstante, consideramos que resulta trascendente dar cuenta de la dinámica política detrás de la resistencia y posterior aprobación de normas pro derechos indígenas. Si este es el escenario, lo que esperaríamos es que en los próximos ańos se desencadene un proceso de reconocimiento constitucional de derechos indígenas en Chile no solo por un reciente cambio en las relaciones de poder en el Congreso que podrían facilitar su aprobación, ${ }^{15}$ sino también por el cambio en la lógica discursiva de la derecha en materia de reconocimiento. Es probable que la élite política establezca un consenso mínimo de reconocimiento muy centrado en la "multiculturalidad", aunque no en el reconocimiento de Chile como un Estado plurinacional. Asimismo, y tal como ha ocurrido en otros casos, se debe esperar una estrategia de aceptación general del reconocimiento, pero buscando colocar trabas en su implementación.

15 En las elecciones de noviembre de 2013, los legisladores de centro-izquierda obtuvieron 71 de los 120 asientos en la Cámara de Diputados y 21 de 38 asientos en el Senado. Esta correlación de poder no les permite una mayoría suficiente para cambiar el artículo sobre reconocimiento (que requiere 66\% de ambas Cámaras), pero sí un mayor espacio de negociación de una reforma constitucional. 


\section{Referencias}

Anaya, A. (2005). The Emergence and Development of the Politics of Recognition of Cultural Diversity and Indigenous Peoples' Rights in Mexico: Chiapas and Oaxaca in Comparative Perspective. Journal of Latin American Studies, 37(3), 585-610.

Antileo, E. (2012). Nuevas formas de colonialismo. Diáspora mapuche y el discurso de la multiculturalidad. Tesis para optar al grado de magister en Estudios Latinoamericanos. Santiago: Universidad de Chile.

Bello, A. (2004). Etnicidad y ciudadanía en América Latina: La acción colectiva de los pueblos indigenas. CEPAL/ONU.

Bello, A. (2011). Nampulkafe. El viaje de los mapuches de la Araucania a las pampas argentinas. Temuco: Ediciones uc Temuco.

Bengoa, J. (2000). La emergencia indígena en América Latina. Santiago: Fondo de Cultura Económica.

Bengoa, J., Caniguan, N. \& Alliende, M. de los Á. (2012). Mapuche, procesos, politicas y culturas en el Chile del bicentenario. Santiago: Catalonia.

Boccara, G. (1999). Políticas indígenas en Chile (siglos xIx y xx) de la asimilación al pluralismo. El caso Mapuche. Revista de Indias, 59(217), 741-774.

Burguette, A. (2008). Gobernar en la diversidad en tiempos de multiculturalismo en América Latina. En Leyva, X., Burguete, A. \& Speed, S. (Coords.). Gobernar (en) la diversidad: experiencias indígenas desde América Latina. Hacia la investigación de co-labor (pp. 15-64). México: Flacso Guatemala/Flacso Ecuador/CIESAS.

Correa Sutil, S. (2011). Con las riendas en el poder. La derecha chilena en el siglo XX. Santiago de Chile: Randon House Mondadori.

Correa, M. \& Mella, E. (2010). Las razones del Illkun/Enojo. Santiago: Lom Ediciones.

De Cea, M. (2012). La omisión a la diferencia. Elites, discriminación y reconocimiento de pueblos originarios en Chile. Santiago de Chile: Universidad Diego Portales

Donoso, S. (2008). Chile y el convenio 169 de la oiT: reflexiones sobre un desencuentro. Temas de la Agenda Pública, (16), 1-13.

Figueroa, C. (2013). Trazos e imágenes de la nación chilena. El norte grande y la frontera sur 1880-1930. En Figueroa, C. (Ed.). Chile y América Latina, democracias, ciudadanias, y narrativas históricas (pp. 39-76). Santiago de Chile: RIL Ediciones. 
Foerster, R. \& Montecino, S. (1988). Organizaciones, lideres y contiendas mapuches (1900-1970). Santiago de Chile: CEDEM.

Gallardo, V. (2001). Héroes indómitos, bárbaros y ciudadanos chilenos: el discurso sobre el indio en la construcción de la identidad nacional. Revista de Historia Indígena, (5), 119-134.

Hale, Ch. (2002). Does Multiculturalism Menace? Governance, Cultural Rights and the Politics of Identity in Guatemala. Journal of Latin American Studies, 34, 485-524.

Historia de la Ley 20.050. Modifica la composición y atribuciones del Congreso Nacional, la aprobación de los tratados internacionales, la integración y funciones del Tribunal Constitucional y otras materias que indica. Biblioteca del Congreso Nacional de Chile, 2,837 pp.

Huneeus, C. (2000). El régimen de Pinochet. Santiago de Chile: Editorial Sudamericana Chilena.

Instituto de Estudios Indígenas/Universidad de la Frontera. (2003). Los derechos de los pueblos indígenas en Chile. Informe del programa de derechos indígenas. Santiago de Chile: Lom Editores.

Korpi, W. (1998). Power Resources Approach vs. Action and Conflict: On Causal and Intentional Explanations in the Study of Power. En O'Connor, J. S. \& Olsen, G. M. (Eds.). Power Resource ant the Welfare State: A Critical Approach (pp. 37-69). University of Toronto Press.

Marimán, P. \& Aylwin, J. (2008). Las identidades territoriales mapuche y el Estado de chileno: conflicto interétnico en un contexto de globalización. En Leyva, X., Burguete, A. \& Speed, S. (Coords.). Gobernar (en) la diversidad: experiencias indigenas desde América Latina. Hacia la investigación de co-labor (pp. 111-150). México: Flacso Guatemala/Flacso Ecuador/ CIESAS.

Marti, S. (2010). The Emergence of Indigenous Movements in Latin America and their Impact on the Latin American Political Science. Latin American Perspectives, 37(6), 74-92.

Muñoz-Navarro, A. (2008). La nación en el discurso de la derecha. Un análisis del debate parlamentario chileno. Signo y Pensamiento, XXVII(53), 174-192.

Pinto, J. \& Valdivia, V. (2009). ¿Chilenos todos? La construcción social de la nación (1810-1840). Santiago de Chile: LOM Ediciones.

Richards, P. (2013). Race and the Chilean Miracle: Neoliberalism, Democracy and Indigenous Rights. Pittsburgh: Pittsburgh University Press.

Sanhueza, C. (2013). La consulta previa en Chile: del dicho al hecho. En Olea, H. Derecho y pueblo mapuche. Aportes para la discusión. Santiago de Chile: Centro de Derechos Humanos UDP. 
Stuven, A. M. \& Pamplona, M. A. (2000). Estado y nación en Chile y Brasil en el siglo XIX. Santiago de Chile: Universidad Católica de Chile.

Toledo, V. (2007, septiembre). Prima ratio. Movilización mapuche y política penal. Los marcos de la política indígena en Chile 1990-2007. OSAL, viII(22).

Van Cott, D. (2000). The Friendly Liquidation of the Past: The Politics of Diversity in Latin America. Pittsburgh: University of Pittsburgh Press.

Villalba, S. (s. f.). Constituciones multiculturales en América del Sur. Argentina, brasil, colombia, Paraguay y Venezuela. Recuperado de http://campus.usal.es/ -acpa/sites/default/files /CONSTITUCIONES\%20MULTICULTURALES\%20EN\%20AMERICA\%20DEL\% 20SUR.pdf

Yashar, D. (2005). Contesting Citizenship in Latin America: The Rise of Indigenous Movements and the Postliberal Challenge. Nueva York: Cambridge University Press.

Yrigoyen, R. (2009). A los 20 años del Convenio 169 de la OIT: Balance y retos de la implementación de los derechos de los pueblos indígenas en Latinoamerica. Portal de Derecho y Sociedad. Recuperado de www.Alertanet.org.

Recibido el 18 de noviembre de 2014. Aceptado el 18 de julio de 2015. 